\title{
On Cognitive Effects of Metaphor in Advertisements
}

\author{
Yanni Li, a , Zhijuan $\mathrm{Li}^{2}$, Jiayin $\mathrm{Li}^{3}$, Likun $\mathrm{Liu}^{1}$, Zhengpei Chen ${ }^{1}$, Shuang Zhang ${ }^{1}$ \\ ${ }^{1}$ School of Foreign Languages, Changchun Institute of Technology, Jilin 130012, China \\ ${ }^{2}$ School of Foreign Languages, Changchun University, Jilin 130022, China \\ ${ }^{3}$ School of Communication, Jilin Animation Institute, Jilin 130012, China \\ aliyanni2007@163.com
}

\begin{abstract}
Since 2000 years ago, metaphor is regarded as a rhetorical device to add ornament and color to the language. Until the recent twenty years, metaphor is seen as a cognitive device in people's processes of perceiving the world and understanding new things. At the meantime, advertisement becomes an indispensable part in the modern society, while advertising language is the soul of advertisement. In order to achieve the goals of persuasion and consumption, metaphor is widely used in advertising languages by admen. It is so widely spread that arouses great interests of scholars all over the world. They have noticed that an ad with metaphor is more vivid, attractive, informative and persuasive than the one without. The vividness and attractiveness of metaphor can be explained by its rhetorical outlook, but this rhetorical point of view cannot touch the informative and persuasive functions of metaphor. Then the scholars turned their eyes to the cognitive theory of metaphor.
\end{abstract}

Keywords: metaphor; cognition; advertisement; persuasiveness.

\section{Introduction}

Nowadays, people are exposed to various kinds of advertisements, either in TV, newspapers, magazines or on billboards, telegraph poles even on the ground. No matter what forms they take or what language they use, they all intend to persuade us to buy some product or accept some service. Over the past few decades, experts have paid enough attention to the research of advertisements; the advertising languages have especially aroused their great interests. In order to decorate the language and impress people, metaphor is widely used by advertisers in adverting language. However, the researches on metaphors in advertising language only stayed at rhetorical and pragmatic lays, and have not touched any process of how people recognize and accept a metaphor.

Metaphor, as stated in Collins COBUILD English Language Dictionary, is an imaginative way of describing something by referring to something else which has the qualities that you want to express. That is to say there are some implied similarities between a metaphor and the literature expression. The studies on metaphor can be originated to Aristotle, in whose opinion metaphor acts the role of an ornament to enliven the languages. In his book Rhetoric and Poetics (1954), he mainly emphasizes the decorative function of metaphors. As a cognitive tool, a metaphor may help people to understand some novel things easily through the similarities with the already familiar things. If a metaphor is used in an advertisement, it can replace many descriptive words and meanwhile transfer the messages of a product not only vividly but also effectively. That is the right communicative and persuasive functions needed by advertising languages. But the question of how a metaphor helps advertisers to achieve their purposes or what the process of a customer understands the information of advertisements is still have no clear answers[1]. Therefore, the cognitive effects of metaphor in advertising languages are worthy of further research.

\section{Cognitive process of metaphor}

Unlike simile, the words "like” or "as" are not used in a metaphor. Instead, we usually say A is B. The word "is" reflects the cognitive process we get to know things through a metaphor, that we map our understandings or experiences of " $\mathrm{B}$ " (the source domain) to the " $\mathrm{A}$ " (the target domain). In this 
process, the metaphorical projection is decided by people's "bodily and physical experience". They extract some basic concepts from their conceptual systems as the source domains to help them understand the target ones easily. When people get enough familiar with the target domains, those concepts in target domains gradually melt into the basic concepts and can be used as the source domain from then on. That is the transaction from novel metaphor to conventional metaphor (the metaphor that has been already accepted by most people and became a part of daily life). So, when we hear "spend/ waste time", we can understand it immediately rather than trace it to the origin "time is money" first.

We have seen that human's conceptual system is "fundamentally metaphorical" (Lakoff \& Johnson). The metaphor in nature is a cognitive device and a base for human to perceive and conceptualize the world. Metaphors conceptualize the developing world through the projection between two different domains. It entrusts the meaning which not belongs to the target domain in usual times to the target one by developing the associated implications between the source and target domain [2]. So the cognitive nature of metaphor is creating new meanings or new similarities. But for the creation of new meanings and similarities, people cannot understand the unknown world and new things and language will have no change and development.

The creation of new similarities starts with the semantic anomaly of metaphor. Metaphor makes two things that irrelevant to each other superficially stand side by side, which causes the semantic anomaly and stimulates the audience of a metaphor to think over what the similarities are between the two distinct domains. We need the help of metaphorical way of thinking when it is difficult to understand something through the preexisting similarities. The existence of similarities provides us with the possibility of semantic changes. Undoubtedly, they may transfer new meanings to the target domain directly. Even if there is no similarity between the two domains, people also can create similarities in imagination through metaphor. With the help of metaphors, new things can be explained by the extant expressions, and therefore, metaphor forms the power of the development of our language.

\section{The cognitive functions of metaphor in advertisements}

Metaphor is a cognitive device, with which people get to learn new knowledge and acquire new cognition. In the specific context of advertising, the main cognitive functions of metaphor we mentioned before are concluded as the following several points:

\subsection{Informative function}

The first function and task of an advertisement is to convey the information of a product to its audience, so does the metaphor in advertising language. Comparing with ordinary language, a metaphor can use only one word to substitute lots of descriptive sentences while express the same meanings as rich as all the sentences can. A metaphor in an ad is worthy of the power of millions of words. Advertising language should follow the principle of 'KISS (Keep It Short and Sweet)'. That is to say, in order to capture the target audience, an ad should be brief, informative and attractive [3]. While metaphor, with its conciseness and clearness, becomes the best choice of advertisers.

Metaphor with its semantic anomaly can arouse people's interests, stimulate their imagination and evoke their thoughts. Through a metaphor, the target audience of an ad will not only get a vivid image of a product, but also add their own understandings of the vehicle onto the product, thus get more than the admen intend to convey. It turns their attitudes toward ads from positive acceptance to active comprehension and thus highly impresses us.

A metaphor may covey several feelings at one time as it is given rich implied meanings through our imaginations. When we use a metaphor to introduce a new product, it can be understood easily; when we use a metaphor to enliven the advertising language of an old product, it gives us the feeling of improving the quality of the product.

There is another example, "Green shadow which accompanies you". This advertisement wants to express that the skin protector gives you a green shadow which can protect you from sunlight and ultraviolet rays. Under the fierce sunlight, we'd like to relax in a cool place. The blades and branches 
of a tree are a natural umbrella; in its green shadow, we can enjoy the cool and breeze. This advertisement connects the abstract feeling of using the cosmetics with our physical experiences, so as to be impressive and persuasive.

\subsection{Constructing function}

The constructing function of metaphor can be seen as the combination of its cognition nature and cognitive process. Firstly, metaphor causes semantic changes. Metaphor places two distinct domains side by side thus creates semantic anomaly and changes. In the process of understanding a metaphor, people explain one thing in terms of another. That is to say, one domain is given new or extended meanings by this metaphorical thinking. In advertisement, the features or meanings of the vehicle are transferred to the product and therefore enrich its meaning greatly. It can be said like that, metaphor in advertising language constructs a vivid and concrete image of the product for its consumers.

For example, "On Wall Street, if you are out to lunch, you are lunch.” This ad intends to tell people that the commercial competition on Wall Street is so cruel that the loss of one minute, even it is your lunchtime, will lead to your failure in business. But this ad does not mention a word about the fierce competition at all, instead, it uses "lunch" to metaphorically express the failure. To be the lunch of others, to be cut, divided and eaten by the others means totally lost. Although the ad does not show the topic-failure-directly, the metaphor "failure on Wall Street is being the lunch of others" completely conveys the feeling of tension and pressure, and gives us a vivid and humorous warn at the mean time. This metaphor, comparing with the ordinary descriptive words and warns, is undoubtedly powerful.

Secondly, metaphor creates new insights to perceive the world. It doesn't only find out the similarities, but rather providing a new way to understand things. Lakoff has said that it gives "new meanings to our past, to our daily activity and to that we know and believe" [4]. Metaphor pushes people's language and recognitions forward. Products are always new to the market at the beginning. Metaphor in an advertisement entails two things, the known (vehicle) and the unknown (goods, services or ideas). We understand the unknown things through the experiences of the known by projection, and consequently construct an image of the goods, services or ideas as well in the minds. For example, "Breakfast without orange juice is a day without sunshine" (an ad for orange juice). Orange juice gives us the first impression of full of Vitamin C. Vitamin C can increase your immunity, prevent you from catching cold and whiten the skin, which can give you a healthy image. While sunshine at most time symbolizes activity, energy and health. Comparing orange juice to sunlight entrusts the former one the feeling of life, and is more powerful to persuade the audience to accept it.

Though metaphor gives us a vivid image of and a new way to understand the product, it will inevitably hide some features of the product. The best metaphor in advertising language is, through which the target audience may get a relatively complete idea about the product or even to complete it by themselves. So, the choice of the source domain (the vehicle) is decisive.

\subsection{Persuasive function}

The ultimate goal of an advertisement is to achieve persuasion, so is the advertising language. All the wording devices in an ad, besides metaphor, are serving for this aim. Whether this purpose can be achieved or not decides the success or failure of the advertisement.

Metaphor can draw people's attention easily. As we have mentioned for several times, metaphor creates semantic anomaly, which collocates two distinct things together and makes the ad interesting and eye-catching. When the audiences find they are interested in the ad, they would like to continue to know this ad. So we say attention value is the first step for an ad to be successful and persuasive. If an ad is especially made for certain group of people, admen must pay special attentions to the use of metaphor. The choice of metaphor is decided by the similar experiential bases of the target audience.

Besides the attention value, a metaphor should be understandable and acceptable. We know that each advertisement is not assumed to be effective to all the consumers, each of them has their own orientations. But a metaphor is not taken only to attract our eyes, but to convey the messages of the product; it should be meaningful. Therefore, a proper source domain takes the place of the most importance. Through an appropriate metaphor, consumers can get the unseen quality and features of the products very well. Only can the target audience perceive the source domain of a metaphor, the 
mapping between the source domain and the product could happen. And finally achieve the goal of persuasion.

For example, "The most sensational place to wear satin in on your lips” (an ad for a lipstick). This ad first catches our eyes by place satin and lips together. Lips cannot wear anything but be covered by lipsticks. When a lipstick is compared to satin, the slightness, softness, thinness and bright color of satin are given to the lipstick. Applying this brand of lipstick on your lips just likes wearing a silky evening dress which can make you beautiful and sexy. These are the implied meanings of this metaphor. The ad has its target audience, too. They should be those that usually apply lipsticks and also have the experiences about satin, so as to accept this metaphor[5].

\section{Summary}

According to the cognitive viewpoint, metaphor is pervasive in not only our languages, but also our thoughts and actions; our conceptual system is fundamentally metaphorical. The cognitive process of metaphor is mainly the projection of meanings from the source domain onto the target domain, which create semantic anomaly, causes semantic changes between the two domains and bring a new insight to perceive the things. Through metaphor, new meanings are created continuously and therefore promote the development of our languages. Metaphor is widely used by admen in their advertisement. In advertising languages, metaphor constructs a vivid image which is more acceptable and informative for the product. It helps receivers of the Ad find the implied association between the product and the vehicle, and give them free space to add their own understands to the product. By doing these, the goals of advertising - communication and persuasion-will be more effectively achieved.Metaphor in advertisements not only helps people to understand the ad and perceive the product, but also helps give its contribution to other aspects. Metaphor riches the meaning of advertising language to a great extent, makes them eye-catching, vivid, clear, informative, descriptive and acceptable. The features of advertising language that metaphor gives to them strengthen their memorability, readability and persuasiveness. Therefore, make the ad be forceful as promoting tool. Meanwhile, metaphors in advertisement also promote the communication among and comprehension to the culture of nations.

\section{Acknowledgements}

The authors would like to give their thanks to The Education Department of Jilin Province (NO. 2015-201) and Jilin Association for Higher Education (JGJX2015C71) for their financial and technical support.

\section{References}

[1]. Black M. More about Metaphor In A. Ortony (ed). Metaphor and Thought. Cambridge: Cambridge University Press, 1993, 30-35.

[2]. Chen Chunmei. The Application of Cognitive Concept in Advertisements from the perspective of Cognition. Journal of Anyang College of Technology, 2006, 4:119-122.

[3]. Li Yanni, Li Jiayin, Lv Zheng, Li Tianyu and Tang Yanling. Study of Online Accounts Safety and Online Payments by Smart Phones. Journal of Software Engineering, 2015 9(4), p877-885

[4]. Vestergaard T, \& Schroder K, The Language of Advertising .Oxford: Blackwell, 1985, 10-14.

[5]. Li Yan. On Cognitive Function of Metaphor. Journal of Harbin College, 2006, 8: 99-101. 